[薬AKUGAKU 学

$\left[\begin{array}{lrrr}\text { XAKUGAKU } & \text { ZASSHI } \\ 101 & (5) & 482-484 & (1981)\end{array}\right]$

台湾産グンバイヒルガオの成分研究

高木修造, ${ }^{a}$ 山木正枝, ${ }^{a}$ 增田京子, ${ }^{*},{ }^{a}$ 西浜幸江, ${ }^{a}$ 窪田真理子, ${ }^{a}$ 盧 $\quad$ 盛德 ${ }^{b}$

武庫川女子大学薬学部, ${ }^{a}$ 高雄医学院薬学系 ${ }^{b}$

\title{
Studies on the Constituents of Ipomoea biloba Forsk
}

\author{
Shuzo Takagr, ${ }^{a}$ Masae Yamaki,${ }^{a}$ Kyoko Masuda, ${ }^{*}, a$ Yukie Nishinama, ${ }^{a}$ \\ Mariko Kubota, ${ }^{a}$ and Shen-Teh-Lu ${ }^{b}$ \\ Faculty of Pharmaceutical Sciences, Mukogawa Women's University, Edagawa-cho, \\ Nishinomiya-city, Hyogo, Japan and School of Pharmacy, Kaoshung Medical \\ College, Shin-chuan 1st Road, Kaoshung, Taiwan
}

(Received December 15, 1980)

From Ipomoea biloba Forsk, isoquercitrin monoacetate (I), isoquercitrin (II), hyperin (III) and quercetin 3-sodium salt (IV) were isolated.

Keywords_-Ipomoea biloba Forsk; flavonoid glycoside; quercetin glycoside; isoquercitrin monoacetate; hyperin; isoquercitrin; quercetin 3-sodium salt

著者らは先に瀉下生薬の成分研究の一環としてヒルガオ Calystegia japonica $\mathrm{C}_{\mathrm{H}} \mathrm{IrsY}^{1)}$ のフラボノイド配糖体 の研究を行なったが，今回同じヒルガオ科に属する台湾産のグンバイヒルガオI I pomoea biloba FoRsK を入手する 機会を得たので，そのフラボノイド成分の検索を行なった。

グンバイヒルガオは熱帯, 亜熱带の海岸に生育する多年草で, 花はヒルガオに似ており, 葉が軍配の形をして いることからそう呼ばれている，このグンバイヒルガオの地上部をメタノールェキスとしたのち，エーテル可溶 部を除き，水層を酶酸エチル，nーブタノールで順次抽出した。 TLC においてフラボノイド成分が多くみられた 酶酸エチルエキスにつき，くり返しシリカゲルクロマトを行ない黄色結晶（I)，(II), (III) 拈よび (IV)を得た. これらの結晶はすべてフラボノイド反応陽性, 塩化第二鉄反応陽性であり, 酸加水分解によりアグリコンとして quercetin を与兄る。また糖部としてI 特よび II は glucose, III は galactose を与える.

以上の事実および薄層クロマトグラフィー (TLC) のRf 值より II 拉よび III はそれぞれ isoquercitrin (quercetin 3-glucoside) 拉よび hyperin (quercetin 3-galactoside) と推定し, 標品との赤外線吸収スペクトル (IR)，紫外部吸収スペクトル(UV)，TLCの比較および混融により同定した.

つぎにIはIRにおいて $1710 \mathrm{~cm}^{-1}$ にエステルの吸収を有し，また にアセチル基 1 個分に相当するシグナルを示している．そこでI をacetate と考光 $1 \% \mathrm{NaOH}$ で処理し脱つ 七チル体を得た. 本品はTLC 上り先の isoquercitrin と推定し, 標品の isoquercitrin と IR, UV 拈よび混融に より同定した. Acetyl 基の結合位置は I およびIIの ${ }^{13} \mathrm{C}$-核磁気共鳴 (CMR) を比較し (Table I), glucose のC-5 およびC-6 のシグナルにシフトが見られる事から glucose の6 位と決定した. したがってIは quer-

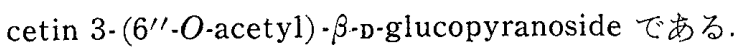

(IV) は酸处理で quercetin を与えること，PMR で糖の存在を示さないことおよび acetate の融点と IR が 標品の quercetin pentaacetate と一致する事から金属塩と考兄, 炎色反応および原子吸光々度法によりナトり ウム塩であることを確認した.ナトリウムの数は FD-Mass に扮いて $\mathrm{M}^{+}$が 324 を示すことから 1 個であると 考えたまたナトリウムの結合位置はUVでメタノ一ル溶液の Band I が $353 \mathrm{~nm}$ で 3 位が监換されていること を示して拈り，また $\mathrm{NaOMe}, \mathrm{NaOAc}, \mathrm{AlCl}_{3}$ 拈よび $\mathrm{AlCl}_{3}+\mathrm{HCl}$ 添加の際のシフトが 3'，4', 5, 7 位の水酸基が いずれも free であることを示している事から 3 位と決定した.2) したがって IV は quercetin 3-O-sodium salt 
TABLE I. $\quad{ }^{13} \mathrm{C}$ Chemical Shift $\left(\delta_{\mathrm{c}}\right)$ in DMSO- $d_{6}$ at $\left.30^{\circ} a\right)$

\begin{tabular}{|c|c|c|c|c|c|c|c|}
\hline & II & I & $\Delta \delta^{()}$ & & II & $\mathrm{I}$ & $\Delta \delta^{c)}$ \\
\hline 2 & 156.3 & 156.5 & & $4^{\prime}$ & 148.4 & 148.5 & \\
\hline 3 & 133.4 & 133.2 & & $5^{\prime}$ & $116.3^{b)}$ & 116.2 & \\
\hline 4 & 177.4 & 177.4 & & $6^{\prime}$ & 121.5 & 121.5 & \\
\hline 5 & 156.3 & 156.5 & & $\mathrm{G}-1^{\prime \prime}$ & 101.0 & 101.1 & \\
\hline 6 & 98.6 & 98.7 & & $2^{\prime \prime}$ & 74.1 & 74.0 & \\
\hline 7 & 164.1 & 164.2 & & $3^{\prime \prime}$ & 76.5 & 76.3 & \\
\hline 8 & 93.5 & 93.6 & & $4^{\prime \prime}$ & 70.0 & 69.8 & \\
\hline 9 & 161.2 & 161.2 & & $5^{\prime \prime}$ & 77.5 & 74.0 & -3.5 \\
\hline 10 & 104.0 & 103.9 & & $6^{\prime \prime}$ & 61.0 & 62.8 & +1.8 \\
\hline $1^{\prime}$ & 121.1 & 121.1 & & $\mathrm{CH}_{3}-\mathrm{CO}-$ & & 20.0 & \\
\hline $2^{\prime}$ & $115.2^{b)}$ & 115.1 & & $\mathrm{CH}_{3}-\mathrm{CO}-$ & & 169.9 & \\
\hline $3^{\prime}$ & 144.8 & 144.8 & & & & & \\
\hline
\end{tabular}

a) Nihon Denshi JNM-PFT-100 Spectrometer (25.15 MHz).

$b$ ) may be interchanged.

c) $\Delta \delta=\delta(\mathrm{I})-\delta(\mathrm{II})$.

である.

以上，台湾産グンバイヒルガオより 3 種の配糖体とナトリウム塩を単離したが，ヒルガオが kaempferol 配糖 体を含むのに対し.1) すべて quercetin の配糖体であったまた著者らはすでに営実より鵍下有効成分 multiflorin A (kaempferol 3-(6"'-O-acetyl)- $\beta$-D-glucosyl-(1-4)- $\alpha$-L-rhamnoside) を単離して拈り, ${ }^{3)}$ その関連性に招 いて今回単離した isoquercetin monoacetate（I）についてもマウスによる潟下試験を行なったが，顕著な効果 は認められなかった。

\section{実験 の 部}

融点（未補正）は柳本微量融点測定装置, IR は島津 IR-27 G, UV は日立自記分光方度計 323 型, 原子吸光々 度計 208 型で測定した. PMR は Varian A-60 A Spectrometer $(60 \mathrm{MHz})$ で tetramethylsilane を内部標準物 質として測定し, 化学シフトは $\delta(\mathrm{ppm})$ で表わした. 万紙クロマトグラフィー (PPC) は東洋ろ紙 No. 51 を用 い, 展開溶媒として $n$ - $\mathrm{BuOH}$-pyridine- $\mathrm{H}_{2} \mathrm{O}(6: 4: 3), n-\mathrm{BuOH}-\mathrm{AcOH}-\mathrm{H}_{2} \mathrm{O}(4: 1: 5$; 上層)を用い, 発色はア二 リン水素フタレート試薬噴霧後, $110^{\circ}$ で 5 分加熱した. TLC は DC-Fertig platten Kieselgel $60 \mathrm{~F}_{254}$ (Merck) を用い，カラムクロマトグラフィーは Kieselgel 60，70-230 mesh (Merck) を用いた.

抽出および分画 1977 年 6 月台湾高雄市郊外飞和いて採集し乾燥したグンバイヒルガオの地上部 $3.6 \mathrm{~kg} を$ $\mathrm{MeOH}$ で抽出し, エキス $1.13 \mathrm{~kg}$ を得た. これに $\mathrm{H}_{2} \mathrm{O}$ を加兄 $\mathrm{Et}_{2} \mathrm{O}$ で抽出し, $\mathrm{Et}_{2} \mathrm{O}$ エキス $260 \mathrm{~g}$ を得水層 は AcOEt, $n$-BuOH で順次抽出し, AcOEt エキス $69.8 \mathrm{~g}, n-\mathrm{BuOH}$ エキス $78.5 \mathrm{~g}$ を得た. AcOEt エキスをシ リカゲルカラムクロマトに付し， $\mathrm{CHCl}_{3}-\mathrm{MeOH}(12: 1)$ で溶出する画分 [A] $6.9 \mathrm{~g},(10: 1)$ で溶出する画分 [B] $16 \mathrm{~g},[\mathrm{C}] 9 \mathrm{~g} ，(8: 1)$ で溶出する画分 [D] $1.4 \mathrm{~g}$ を得た．画分 [A]，[B]，[C] 括よび [D] については，それぞ れシリカゲルを用い，展開溶媒として $\mathrm{CHCl}_{3}-\mathrm{MeOH}$ 混液を用いたクロマトグラフィーを繰り返し，結晶 (I) 86 $\mathrm{mg}$, (II) $75 \mathrm{mg}$, (III) $56 \mathrm{mg}$ 扰よび (IV) $18 \mathrm{mg}$ を得た. 以下にそれらの性状を示す.

Isoquercitrin Monoacetate (I) 黄色針状晶, $\mathrm{mp} 230-231^{\circ}(\mathrm{MeOH}), \mathrm{Mg}-\mathrm{HCl}$ 反応 (+). Anal. Calcd $\mathrm{C}_{23} \mathrm{H}_{22} \mathrm{O}_{13} \cdot 1 / 3 \mathrm{H}_{2} \mathrm{O}: \mathrm{C}, 53.90 ; \mathrm{H}, 4.29$. Found: $\mathrm{C}, 54.02 ; \mathrm{H}, 4.24$. UV $\lambda_{\max }^{\text {Meor }} \mathrm{nm}(\log \varepsilon): 259$ (4.33), $268 \mathrm{sh}$ (4.30), $300 \mathrm{sh}$ (3.95), $360(4.25)$. IR $\nu_{\max }^{\mathrm{KBr}} \mathrm{cm}^{-1}: 3400-3100$ (broad, OH), $1710\left(-\mathrm{OCOCH}_{3}\right), 1660,1605$. PMR (DMSO- $\left.d_{6}\right) \delta \mathrm{ppm}: 1.70\left(3 \mathrm{H}, \mathrm{s},-\mathrm{OCOC}_{3}\right), 3.50-4.10\left(6 \mathrm{H},>\mathrm{C} \underline{\mathrm{H}}-,-\mathrm{CH}_{2}-\right), 5.38(1 \mathrm{H}, \mathrm{d}, J=7.0 \mathrm{~Hz}$, anomeric- $-\mathrm{H}), 6.20\left(1 \mathrm{H}, \mathrm{d}, J=2.0 \mathrm{~Hz}, \mathrm{C}_{6}-\mathrm{H}\right), 6.42\left(1 \mathrm{H}, \mathrm{d}, J=2.0 \mathrm{~Hz}, \mathrm{C}_{8}-\mathrm{H}\right), 6.84\left(1 \mathrm{H}, \mathrm{d}, J=9.0 \mathrm{~Hz}, \mathrm{C}_{5^{\prime}}-\mathrm{H}\right)$, $7.58\left(1 \mathrm{H}, \mathrm{d}, J=2.0 \mathrm{~Hz}, \mathrm{C}_{2}{ }^{\prime}-\mathrm{H}\right), 7.59\left(1 \mathrm{H}, \mathrm{d} . \mathrm{d}, J_{2},^{\prime} 6^{\prime}=2.0 \mathrm{~Hz}, J_{5^{\prime}}{ }^{\prime} 6^{\prime}=9.0 \mathrm{~Hz}, \mathrm{C}_{6}{ }^{\prime}-\mathrm{H}\right)$.

I の脱アセチル化 (Isoquercitrin の生成) I $15 \mathrm{mg}$ に $1 \% \mathrm{NaOH} 0.5 \mathrm{ml}$ を加兄 30 分間室温に放置. 反応 液を $1 \% \mathrm{HCl}$ で pH 3 飞調整後 AcOEt で抽出. 濃縮し $8 \mathrm{mg}$ を得. 本品は標品の isoquercitrin と UV, IR お。 よびTLCで比較一致した，また混融でも融点降下を示さなかった。

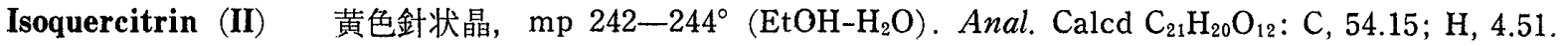


Found: C, 53.94; H, 4.46. UV $\lambda_{\max }^{\mathrm{MeOH}} \mathrm{nm}(\log \varepsilon): 260(4.30), 270 \mathrm{sh}(4.25), 300 \mathrm{sh}(3.93), 362(4.21)$. IR $\nu_{\max }^{\mathrm{KBr}}$ $\mathrm{cm}^{-1}: 3400-3200$ (broad, OH) $1650,1590,1555,1490$. PMR (TMS ether, $\mathrm{CCl}_{4}$ ) $\delta$ ppm: $3.50-3.65(6 \mathrm{H}$, $\left.>\mathrm{CH}-,-\mathrm{CH}_{2}-\right), 5.90(1 \mathrm{H}, \mathrm{d}, J=7.0 \mathrm{~Hz}$, anomeric $\mathrm{H}), 6.14\left(1 \mathrm{H}, \mathrm{d}, J=2.5 \mathrm{~Hz}, \mathrm{C}_{6}-\mathrm{H}\right), 6.43(1 \mathrm{H}, \mathrm{d}, J=2.5 \mathrm{~Hz}$, $\left.\mathrm{C}_{8}-\mathrm{H}\right), 6.85\left(1 \mathrm{H}, \mathrm{d}, J=8.5 \mathrm{~Hz}, \mathrm{C}_{5}{ }^{\prime}-\mathrm{H}\right), 7.48\left(1 \mathrm{H}, \mathrm{d}, J=2.0 \mathrm{~Hz}, \mathrm{C}_{2}{ }^{\prime}-\mathrm{H}\right), 7.63\left(1 \mathrm{H}, \mathrm{d} . \mathrm{d}, J_{2^{\prime}}{ }^{\prime} 6^{\prime}=2.0 \mathrm{~Hz}, J_{5^{\prime}}, 6^{\prime}=\right.$ $\left.8.5 \mathrm{~Hz}, \mathrm{C}_{6}{ }^{\prime}-\mathrm{H}\right)$.

Hyperin (III) 黄色針状晶, mp 248-250 (EtOH). Anal. Calcd $\mathrm{C}_{21} \mathrm{H}_{20} \mathrm{O}_{12} \cdot \mathrm{H}_{2} \mathrm{O}: \mathrm{C}, 52.28 ; \mathrm{H}, 4.56$. Found: C, 51.95; H, 4.56. UV $\lambda_{\max }^{\mathrm{MeOH}} \mathrm{nm}(\log \varepsilon): 260(4.34), 270 \mathrm{sh}(4.27), 300 \mathrm{sh}(3.94), 362(4.25)$. IR $\nu_{\mathrm{maq}}^{\mathrm{KBr}}$ $\mathrm{cm}^{-1}: 3400-3200$ (broad, OH), 1655, 1610, 1500, 1360. PMR (TMS ether, $\left.\mathrm{CCl}_{4}\right) \delta \mathrm{ppm}: 3.45-3.87(6 \mathrm{H}$, $\left.>\mathrm{CH}_{-}-,>\mathrm{CH}_{2}\right), 5.62(1 \mathrm{H}, \mathrm{d}, J=7.1 \mathrm{~Hz}$, anomeric $\mathrm{H}), 6.14\left(1 \mathrm{H}, \mathrm{d}, J=2.0 \mathrm{~Hz}, \mathrm{C}_{6}-\mathrm{H}\right), 6.47(1 \mathrm{H}, \mathrm{d}, J=2.0 \mathrm{~Hz}$, $\left.\mathrm{C}_{8}-\mathrm{H}\right), 6.80\left(1 \mathrm{H}, \mathrm{d}, J=8.0 \mathrm{~Hz}, \mathrm{C}_{5}{ }^{\prime}-\mathrm{H}\right), 7.34\left(1 \mathrm{H}, \mathrm{d}, J=2.0 \mathrm{~Hz}, \mathrm{C}_{2}{ }^{\prime}-\mathrm{H}\right), 7.78\left(1 \mathrm{H}, \mathrm{d} . \mathrm{d}, J_{5^{\prime}}, 6^{\prime}=8.0 \mathrm{~Hz}, J_{2^{\prime}}, 6^{\prime}=\right.$ $\left.2.0 \mathrm{~Hz}, \mathrm{C}_{6}^{\prime}-\mathrm{H}\right)$.

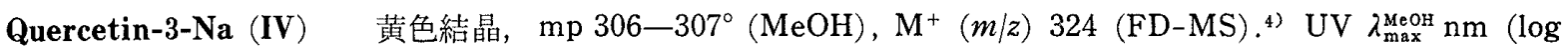
$\varepsilon): 258$ (4.18), $270 \mathrm{sh}(4.14), 354$ (4.15); $\lambda_{\max }^{\mathrm{MeOH}+\mathrm{NaOMe}} \mathrm{nm}(\log \varepsilon): 275$ (4.28), 330 (3.85), 407 (4.24); $\lambda_{\max }^{\mathrm{MeOH}+\mathrm{ACONa}} \mathrm{nm}(\log \varepsilon): 276(4.24), 374(4.08) ; \lambda_{\max }^{\mathrm{MeOH}+\mathrm{AlCl}} \mathrm{nm}(\log \varepsilon): 278$ (4.25), $305 \mathrm{sh}(3.77), 422$ (4.14); $\lambda_{\max }^{\mathrm{MeOH}+\mathrm{AlCl}_{s}+\mathrm{HCl}} \mathrm{nm}(\log \varepsilon): 275$ (4.15), $302 \mathrm{sh}$ (3.81), 360 (3.99), 400 (4.03). IR $\nu_{\max }^{\mathrm{KBr}} \mathrm{cm}^{-1}: 3400-3200$ (broad $\mathrm{OH}), 1655,1605,1500,1355$. PMR (DMSO-d $d_{6} \delta \mathrm{ppm}: 6.13\left(1 \mathrm{H}, \mathrm{d}, J=2.0 \mathrm{~Hz}, \mathrm{C}_{6}-\mathrm{H}\right), 6.34(1 \mathrm{H}, \mathrm{d}, J=2.0$ $\left.\mathrm{Hz}, \mathrm{C}_{8}-\mathrm{H}\right), 6.75\left(1 \mathrm{H}, \mathrm{d}, J=8.0 \mathrm{~Hz}, \mathrm{C}_{5}{ }^{\prime}-\mathrm{H}\right), 7.52\left(1 \mathrm{H}, \mathrm{d}, J=2.0 \mathrm{~Hz}, \mathrm{C}_{2}{ }^{\prime}-\mathrm{H}\right), 7.59\left(1 \mathrm{H}, \mathrm{d}, \mathrm{d}, J_{2^{\prime}}, 6^{\prime}=2.0 \mathrm{~Hz}, J_{6^{\prime}}\right.$, $\left.s^{\prime}=8.0 \mathrm{~Hz}, \mathrm{C}_{6}{ }^{\prime}-\mathrm{H}\right)$.

酸加水分解 I, II および III にそれぞれ 7\% $\mathrm{H}_{2} \mathrm{SO}_{4}$ を加光, 沸騰水浴上 1 時間加熱, 生じた結晶をろ取. 得られた結晶はすべて標品の quercetin と融点, TLC, IR において比較一致. ろ液は Amberlite IRA-410 (OH 型) で中和後濃縮し，I，II より glucose, III より galactose を生成したことを TLC, PPCで確認した.

謝辞本研究に際し， ${ }^{13} \mathrm{C}-\mathrm{NMR}$ の測定ならびに有益な御助言を頂いた広島大学医学部総合薬学科 田中治 教授，山崎和男教授に深謝いたします。また FD-MS の測定をして頂いた塩野義製薬研究所 中川有造博上に 深謝いたします。

\section{引用文献および注}

1) 高杉修造, 山木正枝, 増田京子, 窪田真理子, 薬誌, 97, 1369 (1977).

2) T.J. Mabry, K.R. Markham, M.B. Thomas, “The Systematic Identification of Flavonoids," Springer Verlag, New York, 1970.

3) 高木修造, 山木正枝, 増田京子, 寉田真理子, 薬誌, 96, 1217 (1976).

4) FD ion source を装着した Hitachi RMU-8GM Mass-spectrometer で測定. 電界印加電圧 $6.8 \mathrm{KV}$, Emitter Current 23.4-24.0 mA. 